\title{
A importância da supervisão colaborativa no desenvolvimento profissional do docente de educação especial
}

\author{
Ana Maria Paula Marques Gomes* \\ Maria da Conceição Martins Vieira**
}

\section{Resumo}

As atuais tendências supervisivas apontam para a supervisão entre pares, uma conceção democrática de supervisão que valoriza a reflexão e a aprendizagem em colaboração, levando os professores a gerar e a partilhar atividades e conhecimentos. Acreditamos que o trabalho dos docentes em equipa, centrado na reflexão, poderá promover um desenvolvimento profissional adequado às necessidades individuais e às exigências de uma profissão em que o professor se vê permanentemente confrontado com novas situaçóes e desafios. As práticas colaborativas assentes na troca e partilha de experiências proporcionam aprendizagens diretas, aumentam a quantidade e a qualidade de soluçóes e ideias e a qualidade das opçóes realizadas. Assim, no desenvolvimento desta investigação, de natureza descritiva/interpretativa e numa abordagem predominantemente qualitativa, definimos objetivos distintos e complementares determinados pelo refletir sobre modelos e práticas supervisivas, verificar práticas colaborativas em contexto de sala de educaçáo especial, potenciar a utilização das Tecnologias de Informação e Comunicação (TIC) no trabalho colaborativo e identificar fatores de constrangimento e de facilitação da prática de supervisão colaborativa na sala de educação especial. Dos resultados obtidos no estudo parece-nos fundamental ressaltar que na prática supervisiva deverá existir um diálogo aberto e verdadeiro interpares competindo ao supervisor, enquanto membro do corpo docente com funçốes supervisivas, transmitir a ideia de que todo o processo supervisivo interpares não é a avaliação, mas sim um melhor conhecimento do ato educativo, facultando a tomada de decisóes pedagógicas mais adequadas.

Palavras-chave: Práticas colaborativas; Desenvolvimento profissional; Educação especial.

* Professora doutora da Escola Superior de Educaçâo de Paula Frassinetti, Porto, Portugal.

** Coordenadora da àrea de Educação Especial no Agrupamento de Escolas de Gondomar, Porto, Portugal. 


\section{The importance of collaborative supervision in professional development of teachers in special education}

\section{Abstract}

Current trends point to the supervision among peers, one democratic design of supervision that oversight the reflection and learning in collaboration, leading teachers to create and share activities and knowledge. We believe that the work of teachers as a team, focused on reflection, can promote a professional development adequate to individual needs and requirements of a career in which the teacher finds himself constantly confronted with new situations and challenges. The collaborative practices based on the exchange and sharing of experiences provide direct learning, increase the quantity and quality of solutions and ideas and the quality of the options performed. Thus, in the development of this research, of descriptive/interpretative nature and in a predominantly qualitative approach, we defined distinct and complementary objectives determined by the reflect about models and supervisory practices, verify collaborative practices in context of special education room, promote the use of Information and Communication Technologies (TIC) in collaborative work and identify constraining and facilitating factors in the practice of collaborative supervision in special education room. From the results obtained in this study it seems crucial to emphasize that in supervision practice there should be an open and true dialogue between peers. Is the supervisor responsibility as a member of the school with supervision functions, to convey the idea that the entire supervision process between peers is not evaluation, but instead a better understanding of the education act, providing more appropriate educational decision making.

Keywords: Collaborative practices; Professional development; Special education.

\section{Introdução}

Nos últimos anos letivos a escola tem vivido um (re)despertar do fenómeno supervisivo. Tal tem suscitado um novo interesse quer pelas alteraçóes recentes na legislação portuguesa que regula o Estatuto da Carreira Docente (Decreto-Lei n. 15/2007), a Avaliação de Desempenho do Pessoal Docente (Decreto-Regulamentar n. 2/2008), a alteração ao Regime de Autonomia e Gestão das Escolas (Decreto-Lei n. 75/2008) que colocam a ênfase nas funções supervisivas, nomeadamente ao nível das estruturas de gestão intermédia, quer pela sua função social de instituição ao serviço do desenvolvimento e da formação dos cidadãos. Mais recentemente, o Decreto Regulamentar n. 26/2012, de 21 de fevereiro, diz respeito ao desenvolvimento dos princípios que presidiram ao estabelecimento de um novo regime de avaliação do desempenho docente instituído na $11^{a}$ alteração ao Estatuto da Carreira dos Educadores de Infância e dos Professores dos Ensinos Básico e Secundário. No seu conteúdo, continua a valorizar a importância da supervisão pedagógica, fazendo referência à criação de uma bolsa de avaliadores com formação em supervisão pedagógica. 
É pois, através deste enquadramento jurídico, que a supervisão da prática pedagógica, fora da esfera da formação inicial de professores, ganha outra legitimidade, sendo realizada por docentes profissionalizados e como referem Alarcáo e Roldão (2008), em contexto de trabalho interpares de forma horizontal, distinguindo-se da supervisão vertical praticada nos contextos da formação inicial.

\section{Os cenários da supervisão}

A supervisão (do latim: super $=$ sobre, acima + videre $=$ observar, ver) visa a melhoria das práticas e a mudança da qualidade do ensino/aprendizagem e das escolas.

A tradição de supervisão em Portugal é "de natureza prescritiva e confere ao supervisor o papel dominante na tomada de decisóes sobre quem faz o quê, para quê, como, onde e quando" (VIEIRA, 1993:60). Neste sentido, o termo supervisão, de acordo com Alarcáo e Tavares (2010:3), "evocava conotaçóes de poder e de relacionamento socioprofissional contrárias aos valores de respeito pela pessoa humana e pelas suas capacidades auto-formativas", até porque se encontrava associada a uma prática tradicional como a orientação pedagógica dos professores estagiários. Com efeito, a evolução da supervisão revela-se significativa, porque de movimentos fragmentários, na opinião de Alarcão (2005), torna-se um ato mais compreensivo e de atuação integrada.

Numa palavra, o olhar visto pelo sentido vertical, de cima para baixo, pode ser encarado numa perspetiva hierarquizada. Segundo Sá-Chaves (2007:117) o prefixo "super", da palavra supervisão, não deve ser encarado nesse sentido, onde existe uma relaçáo de superioridade no processo de supervisionar, mas sim "o conceito de distanciamento entre o observador e o observado, que permite o alargamento do campo de análise e a possibilidade da sua compreensão sistémica e contextualizada". A posição de orientação e acompanhamento, no processo formativo, é reforçada por Alarcão e Tavares (2010:16) ao defenderem a ideia de que "um professor, em princípio, mais experiente e mais informado, orienta um outro professor ou candidato a professor no seu desenvolvimento humano e profissional".

O fator social e humano interliga-se com o desenvolvimento profissional, revelando uma nova abordagem na conceção da supervisão. Neste sentido, a principal finalidade da supervisão na opinião de Tracy (2002:33) é dar resposta aos interesses do professor, promovendo "o crescimento e desenvolvimento individual".

Para Vieira (2006), a supervisão tal como o nome indica pressupóe uma "super Visão", um olhar diferente, a visão do sentido, isto é, a direção que se deve conceder às práticas educativas: a transformação pessoal e social.

O objeto da supervisão redefinido por Alarcão e Tavares (2010:144), visa “o desenvolvimento qualitativo da instituição escolar e dos que nela realizam o seu trabalho de estudar, ensinar ou apoiar a função educativa por intermédio de aprendizagens individuais e colectivas, incluindo a formação de novos agentes".

Alarcão (2000:17) considera que as mudanças na conjuntura fazem apelo a que a supervisão assuma uma "dimensão colectiva", devendo pensar se a "supervisão 
e a melhoria da qualidade que lhe está inerente, não só à sala de aula, mas a toda a escola, não só aos professores isoladamente, mas aos professores na dinâmica das suas interacçôes $[\ldots]$ ".

Atualmente dá-se importância a um clima harmonioso de partilha, criação e desenvolvimento profissional, onde se constrói e se reforça um percurso amparado e progressivo até à autonomia profissional, pela dinâmica das sinergias entre duas entidades (supervisor e supervisionado) e a interação entre a ação e o pensamento (ALARCÃO; TAVARES, 2010).

Os avanços concetuais da supervisão fazem corresponder a sua essência à função de apoiar e regular o processo formativo. Neste âmbito, promove competências para: a atuação em situaçôes complexas; a observação crítica; a problematização e pesquisa; o diálogo; a vivência de diferentes papéis; o relacionamento plural e multifacetado e o autoconhecimento relativo a saberes e práticas (ALARCÃO; ROLDÃO, 2008).

De natureza questionadora, analítica, interpretativa, teorizadora e reflexiva do trabalho supervisivo, assente num acompanhamento e discussão permanente do processo e da ação e seus resultados, a supervisão parece constituir assim o alicerce para a construçấo do conhecimento profissional como advogam Alarcão e Roldão (idem).

Nas palavras de Sá-Chaves, a supervisão e a atitude supervisiva

"pressupóem um atento e abrangente olhar que contemple e atente
ao perto e ao longe, ao dito e ao nấo dito, ao passado e às hipóteses
de futuro, aos factos e às suas interpretaçoes possíveis, aos senti-
dos sociais e culturais, à manifestaçấo do desejo e à possibilidade/
impossibilidade da sua concretização, ao ser e à circunstância, à
pessoa e ao seu próprio devir." (SÁ-CHAVES, 2007, p. 119).

De facto, as interaçôes entre os intervenientes num diálogo constante e reflexivo, adaptado metodologicamente ao contexto singular único do exercício da profissão, numa atitude simultaneamente presente e distanciada, permitem que se reforce a ideia não só de supervisão da prática pedagógica, mas também de supervisão "da prática educativa” (ALARCÃO; TAVARES, 2010:129).

Com vista ao desenvolvimento profissional e pessoal pela ação (formação), entende-se a supervisão como um processo, assente em vários cenários, nomeadamente: de imitação artesanal; de aprendizagem pela descoberta guiada, behaviorista; clínico; psicopedagógico; pessoalista; reflexivo; ecológico e dialógico (ALARCÃO; TAVARES, 2010).

Os vários modelos de supervisão permitem fazer uma leitura do seu cenário na prática quotidiana. Apesar das particularidades de cada um, todos se completam e permitem clarificar o caminho de cada profissional (Harris, 2002). Neste sentido, nas práticas de supervisão coexistem vários cenários com caraterísticas diferentes mas que se interligam no objetivo e nas finalidades, uma vez que não existem compartimentos estanques entre si. 
O Cenário de imitação artesanal - o formando aprende com o saber de um "mestre", por ser alguém que transmite o seu conhecimento e a sua "arte" a um aprendiz de professor. O Cenário de aprendizagem pela descoberta guiada - póe ênfase na capacidade de descoberta e de imaginaçâo dos formandos que apoiados pelo supervisor, desenvolvem competências de autocrítica, observando e refletindo sobre a prática pedagógica que desenvolvem. O Cenário behaviorista - centra a atividade supervisiva de professores na observação de aulas. O professor é um técnico de ensino, uma vez que segue um roteiro de observação e interpreta o que vê, para melhorar o seu desempenho em idênticas situaçóes de ensino/aprendizagem. No Cenário clínico - a sala de aula é vista como uma "clínica", onde todos os fenómenos ocorridos e observados são analisados e discutidos na intenção de melhorar a prática de ensino desenvolvida pelos professores. A análise feita pelo professor e supervisor implica o ciclo de observação por fases: encontro pré observação; observação; análise dos dados e planificação da estratégia de discussão; encontro pós observação; análise do ciclo de supervisão (RODRIGUES, 2001). No Cenário psicopedagógico - os professores baseiam o seu desempenho em princípios psicopedagógicos fundamentais. $\mathrm{O}$ supervisor deve ajudar o professor em formação a encontrar assertivamente as soluçôes adequadas às questôes e problemas que surgem no seu quotidiano, num clima de partilha de conhecimentos, numa relação dialogante. Este cenário implica três etapas: preparar; discutir e avaliar o ciclo de supervisão. A finalidade principal da supervisão pedagógica é, na opinião de Alarcão e Tavares (2010:28), "ensinar os professores a ensinar" isto é, a relação do professor com o supervisor e a relação do professor com os seus alunos promove um desenvolvimento no processo ensino/aprendizagem. O Cenário pessoalista - preconiza a formação dos professores influenciada por várias correntes: filosofia, antropologia cultural, psicologia e fenomenologia. Tem por base a perspetiva cognitivista e construtivista, o autoconhecimento é fundamental para o desenvolvimento psicológico e profissional, uma vez que os seus valores, crenças, atitudes e motivaçóes compõem o universo que é o professor (ALARCÃO; ROLDÃO, 2008; OLIVEIRA, 2000). O Cenário reflexivo - promove a reflexão dialogante do professor de si para si, refletindo sobre o que se faz, como se faz e para que se faz. Visando a melhoria das suas práticas profissionais e atendendo à imprevisibilidade da profissão pelos variados contextos, o professor necessitará de uma atuação "inteligente e flexível, situada e reactiva” (ALARCÃO; TAVARES, 2010:35). Este modelo tem por base o pensamento de Schön (1997), a abordagem reflexiva na formação dos profissionais como forma de desenvolver, sistematicamente, no contexto profissional, um conhecimento científico e pedagógico aliado à reflexão. A dinâmica entre o pensamento e a ação é interativa e permanente. O papel do supervisor é importante, uma vez que ajuda, pela reflexão, os professores/formandos a confrontarem situações reais com possíveis falhas e a encontrar estratégias que lhes permitam suplantá-las. O Cenário ecológico desenvolvido por Alarcão e Sá Chaves (1994) e, mais tarde, por Oliveira Formosinho (2002), centra-se nas dinâmicas sociais, uma perspetiva ecológica do processo formativo. Neste contexto, de acordo com Alarcão e Tavares (2010:37), a "supervisão [...] assume a função de proporcionar e gerir experiências diversificadas, em contextos variados". O supervisor deve direcionar os formandos para o agir dinâmico, facilitando a compreensão do que acontece nos microssistemas educativos sem esquecer 
a influência de tudo o que lhe é exterior. Inspirado no Modelo de Desenvolvimento Humano de Bronfenbrenner (1989), este cenário centra-se nas dinâmicas sociais e no processo sinergético que se estabelece na interação entre o sujeito, em desenvolvimento, e o meio que o envolve (micro, meso, exo, macro), sendo que um e outro (o sujeito e o meio) estáo em permanente transformação, a diferentes níveis e com diferentes implicações. O Cenário dialógico - assume no seu modelo de intervenção a importância do diálogo crítico e atribui à linguagem um papel muito importante na construção da cultura e do desenvolvimento. Os professores são vistos como agentes sociais e os supervisores, centram a sua atenção na análise dos contextos. Neste paradigma todos os parceiros se assumem enquanto elementos da mesma comunidade, onde não está ausente a relação dialógica entre pares, professores e supervisores. Este processo formativo pode contribuir para desenvolver competências emancipatórias, proporcionando a cada professor a possibilidade de crescer individual e coletivamente, através da comunicação, da linguagem e do diálogo crítico na construção da cultura profissional. Por último, é pertinente referir o Cenário integrador de Sá-Chaves (2002) que sobre ele desenvolveu, segundo Alarcấo e Tavares (2010, p. 43) o conceito de supervisão não standard, ou seja, "um modelo algo inacabado e susceptível de auto regulação constante através de uma persistente atitude de questionaçáa”. De acordo com este modelo, o conceito de supervisão joga-se na interação entre o pensamento e a ação, tenta dar sentido ao vivido e ao conhecimento, isto é, pretende compreender melhor a profissionalidade docente e as dinâmicas das instituiçôes educativas para agir melhor sobre esses contextos.

Subjacentes a estes cenários/modelos supervisivos encontram-se diferentes conceçôes relativas à relação entre teoria e a prática; à formação e investigação; à noção de conhecimento como saber constituído e transmissível ou construção pessoal de saberes; aos papéis do supervisor/professor; às noçôes de educação e de formação de professores ou supervisores; à assunção da escola como centro de formação ou como mera estaçáo de serviço à formação ou como comunidade reflexiva e aprendente (ALARCÃO; TAVARES, 2010).

Independentemente dos diferentes cenários/modelos de práticas existentes o que parece comummente consensual é a relevância do processo supervisivo na construção e desenvolvimento do professor enquanto indivíduo aprendente, colaborativo e reflexivo.

\section{A supervisão colaborativa na educação especial}

A evolução verificada no âmbito da supervisão pedagógica e a emergência da sua faceta colaborativa e reflexiva contraria a solidáo do professor em busca do seu desenvolvimento pessoal e profissional. De acordo com Alarcão e Roldão (2008), a relação que se estabelece entre dois profissionais num processo supervisivo não deve ser encarada como unilateral e diretiva, mas sim como um processo conjunto de (des) (re)construção do conhecimento profissional baseado numa colegialidade horizontal, reflexiva e democrática. A aprendizagem passa, desta forma, a ser bilateral e contínua, permitindo quer ao supervisor, quer ao professor, uma responsabilidade partilhada na construção do conhecimento profissional. 
A multiplicidade de funçôes desempenhadas pelo professor de educação especial é considerável e depende não só do profissional em si mas, também, do contexto escolar em que se insere. O docente de educação especial, hoje em dia, e de acordo com Correia (2008) deve prestar um apoio mais indireto (de consultadoria a professores e pais, de cooperação no ensino) do que direto, quando se trata de responder com eficácia às necessidades dos alunos com Necessidades Educativas Especiais (NEE) de caráter permanente.

Neste sentido, as funçóes dos professores de educação especial compreendem o planeamento e desenvolvimento programáticos, implementação do programa, serviços de avaliação e de orientação, açôes de supervisão, comunicação e coordenação e ensino direto.

Em síntese, o professor de educação especial deve ter uma visão global, ter claramente definidos os objetivos e, simultaneamente, orquestrar os pequenos detalhes. Este perfil exige que o profissional manifeste elevado nível de competências profissionais, o que engloba as componentes, técnica e comunicacional.

O estudo que apresentamos, no âmbito da supervisão pedagógica inseriu-se num quadro de investigação de natureza descritiva/interpretativa e numa abordagem predominantemente qualitativa, centrando-se na recolha de opiniōes com a finalidade de conhecer e analisar as perceçôes de cinquenta e dois docentes de educação especial, no que diz respeito à importância que este grupo atribui à supervisão colaborativa no seu desenvolvimento profissional.

Centra-se sobretudo em procedimentos interpretativos e heurísticos de análise e interpretação dos dados, sem prejuízo de, sob o ponto de vista metodológico, recorrer a procedimentos estatísticos para maior evidência e reforço do sentido e significado desses mesmos dados, designadamente dos que serão recolhidos através do inquérito por questionário. Assume-se, assim, a lógica de continuum metodológico, preconizada por Huberman e Miles (1991), uma vez que, procedimentalmente, não existe oposição entre dados tratados qualitativa e quantitativamente, considerando que estas perspetivas se apoiam mutuamente.

A estratégia de investigação adotada seguiu a metodologia de estudo de caso que, de uma maneira geral, se fundamenta nos pressupostos e propósitos da investigação interpretativa, definida como "particularística, isto é, que se debruça deliberadamente sobre uma situação específica [...] procurando descobrir o que há nela de mais essencial e característico e, desse modo, contribuir para a compreensão global de um certo fenómeno" (PONTE, 1994:2) e numa abordagem empírica, uma vez que "investiga um fenómeno atual no seu contexto real [...] e no qual, são utilizadas muitas fontes de dados" (YIN, In CARMO; FERREIRA, 1998, p. 216).

Assim, neste estudo, para além da análise literária para melhor definir e enquadrar o estudo empírico procedemos, inicialmente, à construçáo/elaboração de um inquérito por questionário-piloto a fim de valorar o conteúdo e redação de cada item; posteriormente à (re)construção do questionário-definitivo; à preparação e construção de um guiấo de entrevista semiestruturado direcionado a docentes que exercem 
funçóes na sala de educação especial numa Escola Básica de $2^{\circ}$ e $3^{\circ}$ Ciclo ${ }^{1}$, do distrito do Porto; e por fim, à análise dos resultados obtidos do questionário e do conteúdo das entrevistas realizadas.

Tendo em consideração o objeto de estudo e a sua natureza, constituíram-se como objetivos do presente trabalho, refletir sobre modelos e práticas supervisivas, verificar práticas colaborativas em contexto de sala de educação especial de uma escola EB 2/3, potenciar a utilização das Tecnologias de Informação e Comunicação (TIC) no trabalho colaborativo e identificar fatores de constrangimento e de facilitação da prática de supervisão colaborativa na sala de educação especial, durante o ano letivo $2011 / 2012$.

A seleção da amostra não teve como objetivo ser representativa de uma determinada população ou universo, mas antes auscultar, conhecer e analisar as perceçóes, crenças e representaçóes de alguns professores de educação especial, nomeadamente no que diz respeito à importância da supervisão colaborativa no seu desenvolvimento profissional.

Trata-se de uma amostra não probabilística e de conveniência. A análise ao índice de consistência interna - alpha de Cronbach - através do software SPSS (Statistical Package for the Social Sciences), permitiu-nos concluir uma boa correlação entre os itens do questionário, com um $\alpha$ igual a 0,816 .

A versão definitiva do instrumento apresentou uma estrutura esquematizada nas seguintes dimensóes:

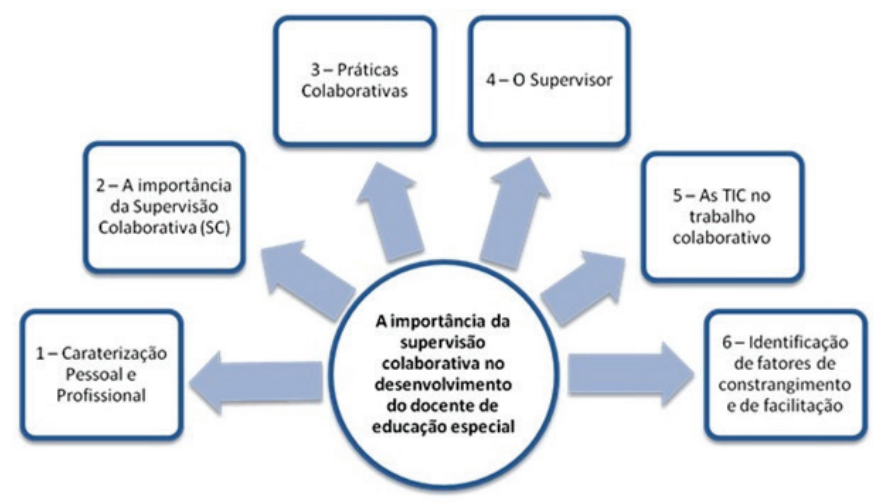

Figura 1: dimensōes do inquérito por questionário.

Assim, o inquérito por questionário foi composto por um conjunto de afirmaçóes, agrupadas em seis dimensóes. As cinco primeiras encontram-se estruturadas num total de vinte e nove itens, que solicitam resposta numa escala de Likert. $\mathrm{Na}$ sexta dimensão, que se encontra dividida em duas, os inquiridos poderiam expressar a sua opinião livremente, por terem maiores condiçôes de liberdade de expressão. As respostas foram sistematizadas em categorias, em função da respetiva análise de conteúdo que consideramos, tal como defende Vala (2001), particularmente útil, uma 
vez que não seria possível antecipar todas as formas de expressão que podem assumir as representações dos sujeitos inquiridos.

A recolha e tratamento dos dados do inquérito por questionário possibilitou-nos a conjugação de análises quantitativas com análises qualitativas, o que nos pareceu ser esta opção a mais adequada, em virtude das opiniốes proporcionadas pela análise quantitativa poderem ser complementadas, de algum modo, pela análise qualitativa.

Também utilizámos a técnica da entrevista semiestruturada que segundo Quivy \& Campenhoudt (2003), é a mais utilizada quando se pretende analisar o sentido que os sujeitos dão a problemas específicos. A entrevista adquire assim importância no estudo de caso, pois através dela o investigador percebe a forma como os sujeitos interpretam as suas vivências (BOGDAN; BIKLEN, 1994).

\section{Resultados e considerações finais}

Com predomínio do género feminino (80\%) e um grupo de professores com mais de 45 anos de idade (54\%), a pós-graduação (56\%) é o grau académico com maior incidência, 30\% com mestrado e 14\% com licenciatura. Quanto ao tempo de serviço, 46\% tem mais de 20 anos, e 32\% de 11 a 20 anos de serviço. Sobre o tempo de serviço na educação especial, $40 \%$ possuem menos de 5 anos, por oposição a $10 \%$ que pertencem ao grupo de educaçáo especial há mais de 20 anos.

Sobre a análise da Dimensão - A importância da Supervisão Colaborativa (SC) - todos os inquiridos exibiram fatores de concordância positivos sobre a SC como promotora do desenvolvimento profissional do docente de educação especial, que proporciona uma reflexão sobre as práticas desenvolvidas em contexto de sala de educação especial. Concordam que pode contribuir para vencer as dificuldades que surgem no dia-a-dia, dado que encoraja os professores a experimentar coisas que nunca fariam sozinhos e cuja finalidade última será a de proporcionar uma reflexão colaborativa, assente no respeite mútuo e no reconhecimento do trabalho do outro. A maioria concorda que a SC é fundamental para o desenvolvimento qualitativo da escola e dos que nela realizam o seu trabalho, bem como que, o desenvolvimento profissional faz-se na relaçáo dialógica de partilha de experiências.

Neste sentido, a maioria dos inquiridos corrobora com a opinião de Alarcão e Tavares (2010) que referem que é fundamental que os professores dialoguem sobre os seus sucessos e insucessos, partilhem experiências entre si cruzando olhares que permitem confrontar aquilo que fazem com aquilo que pensam que fazem.

No que concerne aos dados recolhidos na Dimensão - Práticas Colaborativas - os professores concordam, maioritariamente, que o trabalho colaborativo permite a resolução conjunta de problemas na sala de educação especial, o diálogo interpares náo deve ser centrado em juízos de valor, as atitudes de empatia, apoio e aceitaçáo são fundamentais na construção de um clima de abertura entre os pares, o desenvolvimento profissional faz-se na relaçáo dialógica de partilha de experiências, o conhecimento profissional do professor emerge na e a partir da prática e que, o isola- 
mento dos professores constitui um dos maiores obstáculos ao seu desenvolvimento profissional. A este propósito Hargreaves (1998:189) afirma: "tal como a ostra que neutraliza um grão de areia irritante, cobrindo-o com camadas de pérola, os professores isolados parecem cobrir as suas dúvidas e inadequaçóes irritantes com camadas reconfortantes de ilusão pessoal"

No que diz respeito aos dados analisados na Dimensão - O Supervisor - a esmagadora maioria concorda que o supervisor deve contribuir para a existência de uma relação de confiança que possibilite a participação responsável do professor na sua formaçáo, criar um contexto educativo favorável ao desenvolvimento profissional, promover iniciativas que melhorem a qualidade de educação, criar as condições necessárias para o desenvolvimento de programas e projetos, que a relação interpessoal (supervisor/supervisando) deve pautar-se por uma comunicação aberta e autêntica. A este propósito Alarcão e Tavares (2010: 61) referem que "a atmosfera afectivo-relacional e sócio-cultural [...] condicionam negativa ou positivamente todo o processo, [sendo necessário criar-se] um clima favorável" em todo o processo de supervisão.

No que respeita aos dados recolhidos na Dimensão - As TIC no trabalho colaborativo - verificamos que a maioria dos docentes concordam que, estas funcionam como veículo facilitador no trabalho colaborativo, contribuem para melhorar o desenvolvimento profissional do docente de educaçấo especial, permitem aumentar a aproximação entre os mesmos, facilitam a troca ativa de ideias e estimulam o trabalho colaborativo. Em síntese, podemos referir que a maioria dos inquiridos considera que o recurso às TIC aumenta a aproximaçáo entre este grupo de docentes favorecendo, deste modo, o trabalho colaborativo.

Sobre - Identificar fatores de constrangimento e de facilitação - subjacente à prática de supervisão colaborativa, podemos aferir que os professores inquiridos apontam com maior frequência a ausência de diálogo, de partilha, de trabalho em equipa, em suma, uma ausência de uma cultura de colaboração. No que respeita à identificação de fatores de facilitação, a maioria aponta a partilha, a colaboração, a sinceridade, a confiança, a disponibilidade, o reforço positivo e o diálogo.

Do resultado da análise de conteúdo às entrevistas, destacamos algumas opiniôes "o atual modelo de supervisão/avaliação de professores, é um processo mais economicista e menos centrado na efetiva melhoria do sistema de ensino e práticas docentes [...], o que gera uma enorme desmotivaçáo e uma competiçáo pouco saudável entre os professores, fazendo perigar o processo colaborativo entre os mesmos" (E1), "[...] parece-me imprescindível que o supervisor não seja visto como aquele que inspeciona, que está ali para criticar ou emitir juízos de valor [...] mas antes como alguém, em princípio, mais experiente e mais informado, que, numa reflexão colaborativa, assente no respeito mútuo, permite e ajuda de modo construtivo o professor avaliado a refletir e pensar acerca da sua ação educativa, de forma a melhorar a qualidade do seu trabalho e incentivar o seu desenvolvimento profissional e mesmo pessoal" (E2). Nesta linha de pensamento, Alarcão e Tavares (2010:148) defendem que o supervisor deverá desempenhar um papel que pressuporá "o empenhamento e a partilha de opinióes e práticas que se constituem em processos de aprendizagem e de construção colaborativa de saberes". 
Relativamente à colaboração interpares no âmbito da educação especial, "sou totalmente a favor, porque tal prática possibilita uma maior e melhor aprendizagem entre os pares, assim como, um reforço da relação sócio afetiva [...] a existência de um clima de trabalho colaborativo na sala de aula e, em particular na de educação especial, baseado na confiança e no apoio mútuo é muito importante para o crescimento profissional de ambos, uma vez que ninguém se desenvolve num clima de isolamento"(E1) "[...] as atividades são planeadas em conjunto e tudo o que diz respeito à parte burocrática (horários, planificações, relatórios, informaçóes/avaliaçôes de alunos, contactos com os pais, com os Diretores de Turmas, etc.) é feito em colaboraçáo"(E2) "[...] Os nossos encontros informais [...] de questionamento sobre as nossas práticas constituem-se num espaço de partilha estimulando a vontade de fazer ainda melhor [...](E2).

Para estes professores a relação de confiança revela-se essencial para que sejam capazes de partilhar as suas perceçóes acerca das aulas e acerca de novas perspetivas curriculares, uma vez que ninguém se desenvolve num clima de isolamento. "Os professores, como adultos, não aprendem tanto com a frequência de cursos ou a leitura de livros e revistas, mas sobretudo com a observação, análise e reflexão do seu próprio ensino ou do praticado pelos seus colegas" (ALARCÃO; TAVARES 2010:121).

Os professores entrevistados apontam como principais fatores de constrangimento a incompatibilidade de feitio, o caráter, a personalidade, e o próprio processo de avaliação dos mesmos. Como fatores de facilitação consideram o diálogo, a disponibilidade, e a comunicação.

De acordo com Boavida e Ponte (2002), para assegurar que o trabalho colaborativo tenha sucesso, é necessário que cada um dos elementos sinta que o seu envolvimento vale a pena pelos benefícios que daí obtém, bem como pela forma como sente que contribuiu para o grupo.

Relativamente aos benefícios na utilização das TIC no trabalho colaborativo em educação especial os professores auscultados são de opinião de que é um recurso muito útil para esclarecer e partilhar ideias e dúvidas num curto espaço de tempo. Este recurso informático representa um aumento da motivação e da responsabilização, a consistência na planificação e um feedback mais personalizado. $\mathrm{Na}$ opinião de Okada (2009:62) as "TIC funcionam como interfaces, consolidando as inter-relaçóes pessoais, as interaçôes, a interatividade e a construção de sentidos e de significados, além dos recursos de produçáo e comunicação".

Como propostas para potenciar a supervisão colaborativa, os professores defendem a ideia de que a supervisão interpares deveria ser encarada como um processo de formação e desenvolvimento pessoal e profissional sem que exista uma relação hierárquica com cariz avaliativo da supervisão.

Não foi nossa pretensão encontrar conclusôes generalizáveis, nem obter princípios universais, uma vez que, o que nos interessou nesta investigação foi saber a opinião de alguns professores de educação especial sobre a supervisão colaborativa e se essa prática supervisiva contribui para o seu desenvolvimento profissional. Tivemos 
sempre em atenção as questôes ético-morais, tentando assegurar algumas normas de conduta privilegiadas pela investigaçáo qualitativa, nomeadamente, no cumprimento das regras respeitantes à confidencialidade/anonimato dos participantes e ao consentimento esclarecido.

Numa sociedade e numa escola democrática é imperioso refletir sobre as práticas educativas, sobre o papel do professor dentro da pluralidade das conceçóes de vida de cada um, das representaçóes do saber e da prática. As visóes de cada professor, por mais incompletas, incertas, inacabadas, incoerentes e frágeis que sejam, deverão ser confrontadas e articuladas numa orientação que dê lugar a decisôes, a conceçôes reflexivas, essencialmente construtivistas, concebendo um conhecimento profissional contextualizado e sistematizado num contínuo e numa dinâmica interativa entre a ação e a reflexão.

\section{Referências}

ALARCÃO, I.; ROLDÃO, M. Supervisão - um contexto de desenvolvimento profissional dos professores. Mangualde: Ediçốes Pedago, 2008.

ALARCÃO, I.; SÁ-CHAVES, I. Supervisão de professores e desenvolvimento humano: uma perspectiva ecológica. In: TAVARES, J. (Org.). Para intervir em Educaçáo. Contributos dos Colóquios CIDINE. Aveiro: Ediçóes CIDINE, 1994.

ALARCÃO, I. Escola reflexiva e supervisão: uma escola em desenvolvimento e aprendizagem. In: ALARCÃO, I. (Org.). Escola reflexiva e supervisáo: uma escola em desenvolvimento e aprendizagem. Porto: Porto Editora, 2000.

ALARCÃO, I. Formaçáo reflexiva de professores. Porto: Porto Editora, 2005.

ALARCÃO, I.; TAVARES, J. Supervisáo da prática pedagógica - uma perspectiva de desenvolvimento e aprendizagem. Coimbra: Ediçóes Almedina, 2010.

BOAVIDA, A.; PONTE, J. Investigação colaborativa: potencialidades e problemas. In: GTI (Org.). Refletir e investigar sobre a prática profissional. Lisboa: APM, 2002.

BOGDAN, R.; BIKLEN, S. Investigaçáo qualitativa em educaçáo. Porto: Porto Editora, 1994.

BRONFENBRENNER, U. Ecological system theory. Annals of Child Development. 6, 187-249. [S.I.:sn],1989.

CARMO, H.; FERREIRA, M. Metodologia de investigaçáo - guia de auto-aprendizagem. Lisboa: Livraria Faculdade de Psicologia, Universidade Aberta, 1998.

CORREIA, L. A escola contemporânea e a inclusáo de alunos com NEE - consideraçóes para uma educação com sucesso. Colecção Impacto Educacional. Secretaria Regional de Educação e Cultura. Porto: Porto Editora, 2008.

FORMOSINHO, J. A supervisáo na formaçáo de professores I - da sala à escola. Porto: Porto Editora, 2002. HARGREAVES, A. Os professores em tempos de mudança. Lisboa: Macraw Hill de Portugal, 1998.

HARRIS, B. Paradigmas e parâmetros da supervisão em educação. In: FORMOSINHO, J. (Org.). A supervisáo na formaçáo de professores II - da organizaçáo à pessoa. Porto: Porto Editora. 2002.

HUBERMAN, M.; MILES, M. Analyse des données qualitatives - Recueil de nouvelles méthodes. Bruxelas: De Boeck Université, 1991.

OKADA, S. A intermediação pedagógica múltipla no universo das TIC e Moodle. In: OKADA, A. (Org.). Moodle: estratégias pedagógicas e estudos de caso. Salvador: EDUNEB.2009.

OLIVEIRA, M. O papel do gestor pedagógico intermédio na supervisão escolar. In: ALARCÃO, I. et al. (Orgs.). Escola reflexiva e supervisão. Uma escola em desenvolvimento e aprendizagem. Porto: Porto Editora,2000.

PONTE, J. O estudo de caso na investigaçấo em educaçăo matemática. Vol. 3 (I). Editorial Quadrante, 1994.

PORTUGAL. Decreto-Lei n. 15, de 19 de Janeiro de 2007. Diário da República n. 14 - I Série. Ministério da Educação. Lisboa, 2007. 
PORTUGAL. Decreto-Lei n. 26, de 21 de Fevereiro de 2012. Diário da República n. 37 - I Série. Ministério da Educação. Lisboa, 2012.

PORTUGAL. Decreto-Lei n 75, de 22 de Abril de 2008. Diário da República n. 79 - I Série. Ministério da Educação. Lisboa, 2008.

PORTUGAL. Decreto-Regulamentar n. 2, de 10 de Janeiro de 2008. Diário da República n. 7 - I Série. Ministério da Educação. Lisboa, 2008.

QUIVY, R.; CAMPENHOUDT, L. Manual de investigaçấo em Ciências Sociais. Lisboa: Gradiva, 2003.

RODRIGUES, A. A formaçáo de formadores para a prática na formaçáo inicial de professores. Policopiado, 2001.

SÁ-CHAVES, I. Formação, conhecimento e supervisão - contributos nas áreas da formação de professores e de outros profissionais. 2a Ediçăo. Aveiro: Universidade de Aveiro, 2007.

SÁ-CHAVES, I. Práticas de supervisão: tempo e memórias de formação. Porto: Infância e Educação-Investigação e Práticas, n. 4 ,GEDEI, 2002.

SCHÖN, D. Formar professores como profissionais reflexivos. In: NÓVOA, A. (Org.). Os professores e a sua formação. 3a edição. Lisboa: Dom Quixote, 1997.

TRACY, S. Modelos e abordagens. In: OLIVEIRA-FORMOSINHO, J. (Org.). A supervisão na formaçáo de professores I - da sala à escola. Porto: Porto Editora, 2002.

VALA, J. A análise de conteúdo. Porto: Edições Afrontamento, 2001.

VIEIRA, F. Formação reflexiva de professores e pedagogia para a autonomia: para a constituição de um quadro ético e conceptual da supervisão pedagógica. In: VIEIRA, F., et al. No caleidoscópio da supervisão: imagens da formação e da pedagogia. Mangualde: Pedago. 2006.

VIEIRA, F. Supervisáo - Uma Prática Reflexiva de Formação. Rio Tinto: Ediçôes Asa, 1993.

\section{Nota}

${ }^{1} \mathrm{O}$ sistema educativo português compreende a educação pré-escolar, escolar e extraescolar. Dentro da educação escolar, estruturam-se o ensino básico, secundário e superior. $\mathrm{O}$ ensino básico por sua vez compreende três ciclos sequenciais, o $1^{\circ}$ ciclo (quatro anos), o $2^{\circ}$ ciclo (dois anos) e o $3^{\circ}$ ciclo (três anos), (MEC, Lei de Bases do Sistema Educativo, Lei n. 49/2005, de 31 de agosto).

\section{Correspondência}

Ana Maria Paula Marques Gomes - Rua Gil Vicente 138-142, 4000-255, Porto - Portugal.

E-mail:ampaula@esepf.pt - conceicaomv@gmail.com

Recebido em 04 de abril de 2014

Aprovado em 22 de junho de 2015 